[Agr. Biol. Chem., Vol. 35, No. 5, p. 697 703, 1971]

\title{
The Nutritional Efficiency of Cannibalism and an Artificial Feed for the Growth of Tadpoles of Japanese Toad (Bufo vulgaris sp.)
}

\author{
By Yasutoyo Nagai, Shin-ichi Nagai and Tetsusaburo Nishikawa \\ Nippai Laboratory, 640 Higashiterao, Tsurumi, Yokohama \\ Received September 29, 1970
}

\begin{abstract}
Tadpoles of Japanese toad (Bufo vulgaris) were cultured by an artificial feed and by forced cannibalism from the egg until metamorphosis finished. The best growth was found in the artificial feed group, however, the highest feed efficiency was observed in the cannibalism group. The tadpoles were metamorphosed by the culture with amino acid mixture feed but no body weight increase was seen in this case. The nutritional disturbance hindered the metamorphosis.

The relative amino acid composition was constant throughout all the stages of the tadpole growth. The relative amino acid composition of the toad was diversed according to the species. Several unidentified ninhydrine-positive substances were detected on the column chromatograms of amino acid analysis of tadpoles and their adult forms.
\end{abstract}

Toads and frogs are two of the best-studied animals in the field of the amphibian biology ${ }^{1-31}$ and physiology. ${ }^{4}$ Their adults are primarily carnivorous in nature, however, their larvae (tadpoles) are omnivorous in their feeding behavior. A toad, Bufo vulgaris, spawns a surprising number of small eggs in a short period of the breeding season, at least several thousand of them by one female, and commonly a vigorous cannibalism is observed at their larval stage if feeds are short for them. Some decades ago, the tadpoles growth of the edible frog (Bull frog) ${ }^{5}$ had studied widely from a practical point of view, using several natural stuffs as feeds,

1) M. Ichikawa, "Kaeru Gaku," Shokabo, Tokyo (1951).

2) G. K. Noble, "The Biology of the Amphibia,' Dover Publication Inc., New York (1954).

3) M. C. Dickerson, "The Frog Book," Dover Publication Inc., New York (1960).

4) "Physiology of the Amphibia," ed. by J.A. Moore, Academic Press, New York and London (1964).

5) J. Shobu, "Shokuyo Gaeru Yoshokuho," Teiokai, Tokyo (1923). but no detailed attention had been paid about their nutritional efficiency, because their adults had very limitted uses for men. In this study, tadpoles of Bufo vulgaris were cultured by forced cannibalism and by amino acids mixture feed. The nutritional efficiencies were compared with that of the culture by an artificial feed.

\section{MATERIALS AND METHODS}

Tadpoles. Several thousands of fertilized eggs spawned by a couple of Japanese toad, (Bufo vulgaris), in the night of 23rd of March, 1969, at a private pond in Tokyo were collected next morning and they were transferred immediately to this laboratory. Hatching was nearly finished at 31 st of March and new-born tadpoles were separated into groups where each group consisted of a hundred individuals in a plastic vessel, $24 \times 31 \times 12 \mathrm{~cm}$ (width $\times$ length $\times$ depth) containing 3 liters of water.

Parents of African claw toad, (Xenopus laevis), were obtained from Gumma university and the fertilized eggs were spawned in this laboratory. Tadpoles of Bull frog, (Rana catesbeiana), were purchased from a 
market and cultured from two months before the metamorphosis.

Culture method. The feeds were given every day once in the morning except for sunday. Culture water was aerated mildly all the time through a round air-stone which had a size of $2 \mathrm{~cm}$ in diameter and the water was changed every two days with occasional cleaning of vessels. The water temperature was same as room temperature. Generally, the survival rate of tadpoles were more than $95 \%$ at the end of the experimental period.

Feeds and feeding. The artificial feed used was a powdered mixture of fish meal $(60 \%)$, wheat flour $(30 \%)$, dried yeast $(5 \%)$, rice bran $(3 \%)$, vitamin mixture, (Panvitan, 1\%) and McCollum's salts (1\%). This mixture was made in a form of crumble by the addition of water and heat, and then powdered before the use. The amino acid mixture feed was prepared as follows: to an amino acids mixture which had the same amino acid composition as that for the whole carcass analysis of Japanese toad as described later, a half weight of $\alpha$-starch and one tenth of soybean oil was added. The vitamin mixture (Panvitan) and McCollum's salts were also added to make their concentration $1 \%$ each. A preparation thus obtained was mixed well with the equal weight of water and dried for $6 \mathrm{hr}$ at $100^{\circ} \mathrm{C}$, and then powdered for the use.

Tadpoles were cultured by 1) artificial feed, 2) forced cannibalism, 3) fish meal, 4) maize powder, 5) amino acid mixture feed and 6) without any feed given.

The daily amount of the artificial feeds given to each group of tadpoles was approximately $10 \%$ on dry basis to live tadpoles weight. In the forced cannibalism, prey tadpoles were cultured separately by the artificial feed and 10 to 20 prey tadpoles crushed by a mortar were given daily to a hundred individuals in the manner that all the preys given were eaten up in the same day.

Analysis. Nitrogen was determined by micro Kjeldahl method. Amino acids of the whole carcass were analyzed by a Hitachi automatic amino acid analyzer, Model KLA-1, according to Spackman et al. ${ }^{61}$ This sample was prepared as follows: dried whole carcass was powdered and $100 \mathrm{mg}$ of the

6) H. D. Spackman, W. H. Stein and S. Moore, Anal. Chem., 30, 1190 (1958). material was hydrolyzed in a sealed tube with $10 \mathrm{ml}$ of $6 \mathrm{~N}$-hydrochloric acid at $100^{\circ} \mathrm{C}$ for $16 \mathrm{hr}$. After the removal of excess hydrochloric acid under the reduced pressure, the residue was dissolved into $20 \mathrm{ml}$ of $0.1 \mathrm{M}$ citrate buffer, $\mathrm{pH} 2.2$, and filtered through a filter paper, and then $1 \mathrm{ml}$ of this filtrate was charged onto the analyzer.

Dry material was obtained by drying samples at $105^{\circ} \mathrm{C}$ for $8 \mathrm{hr}$. Lipids were measured by the extraction of samples with 100 volumes of a mixture of methanol: chloroform (1:1) for $24 \mathrm{hr}$ at room temperature.

Reagents. Amino acids used were products of Ajinomoto Co., Ltd. Vitamin mixture (Panvitan) was obtained from Takeda Chemical Industries, Ltd. McCollum's salt mixture was purchased from Inagaki Yakuhin Kogyo Co., Ltd. Potato $\alpha$-starch was a product of Saiden Kagaku Co., Ltd. Feed materials and other chemicals employed were ordinary commercial products.

\section{RESULTS}

\section{General growth of Bufo vulgaris tadpoles cultured by different feeds}

The growth curves of the tadpoles cultured by several different feeds are shown in Fig. 1

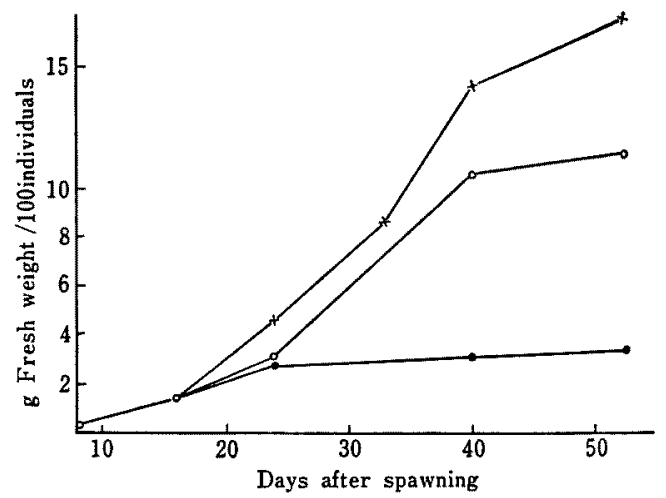

Fig. 1. Growth Curve of Japanese Toad Cultred by Artificial Feed and by Forced Cannibalism (per hundred individuals).

$x-x$, Artificial feed group; $0-0$, Forced cannibalism group; -0, No-feed group.

In abscissa, the approximate progress of growth stages in days after spawned was as followed; 9; hatched 16; feeding started 40 ; hind legs formed 50; fore legs formed 53; tails shrinked. 
where the artificial feed group demonstrates the best growth. The nutrient composition of feeds used are seen in Table I. The tad-

TABLE I. NUTRIEMT COMPOSITION OF THE FEEDS

Crude protein is calculated from nitrogen content.

\begin{tabular}{lcrc}
\hline & $\begin{array}{c}\text { Artificial } \\
\text { feed }\end{array}$ & $\begin{array}{c}\text { Fish } \\
\text { meal }\end{array}$ & $\begin{array}{c}\text { Tadpole } \\
\text { as a prey }\end{array}$ \\
\hline Water $(\%)$ & 12.0 & 6.4 & 92.4 \\
Crude protein $(\%)$ & 48.6 & 65.4 & $30.6^{a}$ \\
Lipid $(\%)$ & 8.9 & 5.2 & $37.0^{a}$ \\
Ash $(\%)$ & 14.0 & 22.6 & $9.2^{a}$ \\
\hline
\end{tabular}

a) Values are expressed as percent in dry basis.

poles were started to be fed from the 16 th day after spawning. During the period after hatching, the tadpoles showed body weight increase without any feeds given which was caused by water uptake. This body weight increase was observed to continue for one week in the no-feed group. In all the tadpole groups tested here, except for the no-feed group, a similar progress of the growth stages was observed with the lapse of time, i.e, the hind legs appeared about 40 days after spawning and forelegs in 50 days, and then tadpoles ceased to eat. The feeding experiments was stopped at this stage and the landing of little toads was seen another one week later.

All of the tadpoles fed only maize powder died before the metamorphosis finished and after the formation of forelegs. No improvement of the tadpoles growth was observed when $1.0 \%$ of tryptophan, $1.5 \%$ of methionine and $5.0 \%$ of lysine were added to maize powder as the feed (all the additives were mixed well with maize powder and water, and the mixture was dried and powdered to feed the tadpoles). The other group fed by fish meal only also died totally just after the complete metamorphosis. The no-feed group did not show the metamorphosis at all and all of them died after the experimental period as little tadpoles without legs. The group fed by the amino acid mixture feed metamorphosed, but the body weight increase was not observed. The forced cannibalism group showed a normal metamorphosis, but the size of toads obtained was smaller than that of the artificial feed group.

\section{Nutritional efficiency of the artificial feeds and cannibalism on tadpole growth}

The nutritional efficiency of several different

\section{Table II. The amount of Nutrients Taken and the Whole Carcass Composition} PER 100 INDIVIDUALS

The tadpoles were killed 53 days after hatching. The feeding started from the 16 th day after hatching. Each group analyzed consisted of a hundred individuals.

\begin{tabular}{|c|c|c|c|c|c|c|}
\hline & $\begin{array}{l}\text { Artificial } \\
\text { feed group }\end{array}$ & $\begin{array}{l}\text { Forced canni- } \\
\text { balism group }\end{array}$ & $\begin{array}{l}\text { Fish meal } \\
\text { group }\end{array}$ & $\begin{array}{l}\text { Amino acid } \\
\text { mixture group }\end{array}$ & $\begin{array}{l}\text { No-feed } \\
\text { group }\end{array}$ & $\begin{array}{c}\text { Larvae just } \\
\text { hatched }\end{array}$ \\
\hline \multicolumn{7}{|l|}{ Nutrients taken $(g)$} \\
\hline Dry matter & 5.550 & 1.088 & 5.986 & 5.500 & 0 & \\
\hline Lipid & 0.302 & 0.372 & 0.406 & 0.344 & 0 & \\
\hline Residue of lipid extraction & 5.248 & 0.716 & 5.580 & 5.156 & 0 & \\
\hline Protein & 2.489 & 0.251 & 3.900 & $(3.465)^{a 1}$ & 0 & \\
\hline \multicolumn{7}{|l|}{$\begin{array}{l}\text { Protein } \\
\text { Found in whole carcass }(\mathrm{g})\end{array}$} \\
\hline Dry matter & 1.320 & 0.852 & 1.314 & 0.533 & 0.236 & 0.210 \\
\hline Lipid & 0.238 & 0.316 & 0.290 & 0.182 & 0.043 & 0.070 \\
\hline Residue of lipid extraction & 1.082 & 0.536 & 1.024 & 0.351 & 0.193 & 0.140 \\
\hline Protein & 0.429 & 0.214 & 0.483 & 0.132 & 0.051 & 0.079 \\
\hline
\end{tabular}

e) grams of amino acids calculated. 
feeds on tadpole growth is compared in Table II where the analyses of feeds given and those of the resultant whole carcass are tabled. The highest feed efficiency was obtained for the cannibalism group which showed inferior growth than for the artificial feed group and in fish meal group. The amount of the feed taken was less in the former group than in the later two groups. A little increase of body weight, measured in dry matter, was found for the no-feed group where lipids and proteins were decreased, but what they had eaten was not known. The amino acid mixture feed group showed quite a little gain in body weight. This feed was slowly dispersible in water and such a physical property of this synthetic diet might be a reason why the nutritional efficiency was so low.

\section{Accumulation of amino acids in tadpoles grown by the cannibalism}

The amount of amino acids accumulated in growing tadpoles cultured by the cannibalism was followed. Each one group of the culture was killed at indicated stages of the growth by addition of ethanol and the whole carcasses prepared by drying at $100^{\circ} \mathrm{C}$ for $8 \mathrm{hr}$ were analyzed as described before. The results of the amino acid analysis are shown in Table III where the constancy of the relative amino acid composition of the tadpoles through all the growing stages is demonstrated. The values are expressed in $\mu$ moles of amino acid per hundred tadpoles and, in parenthesis, the percentages of each amino acid to alanine are shown.

\section{Table III. The Amino Acids Assimlated in Growing Tadpoles BY THE FORCED CANNIBALISM ( $\mu$ mole amino acid per 100 individuals)}

In the parenthesis, the percentage to alanine is given.

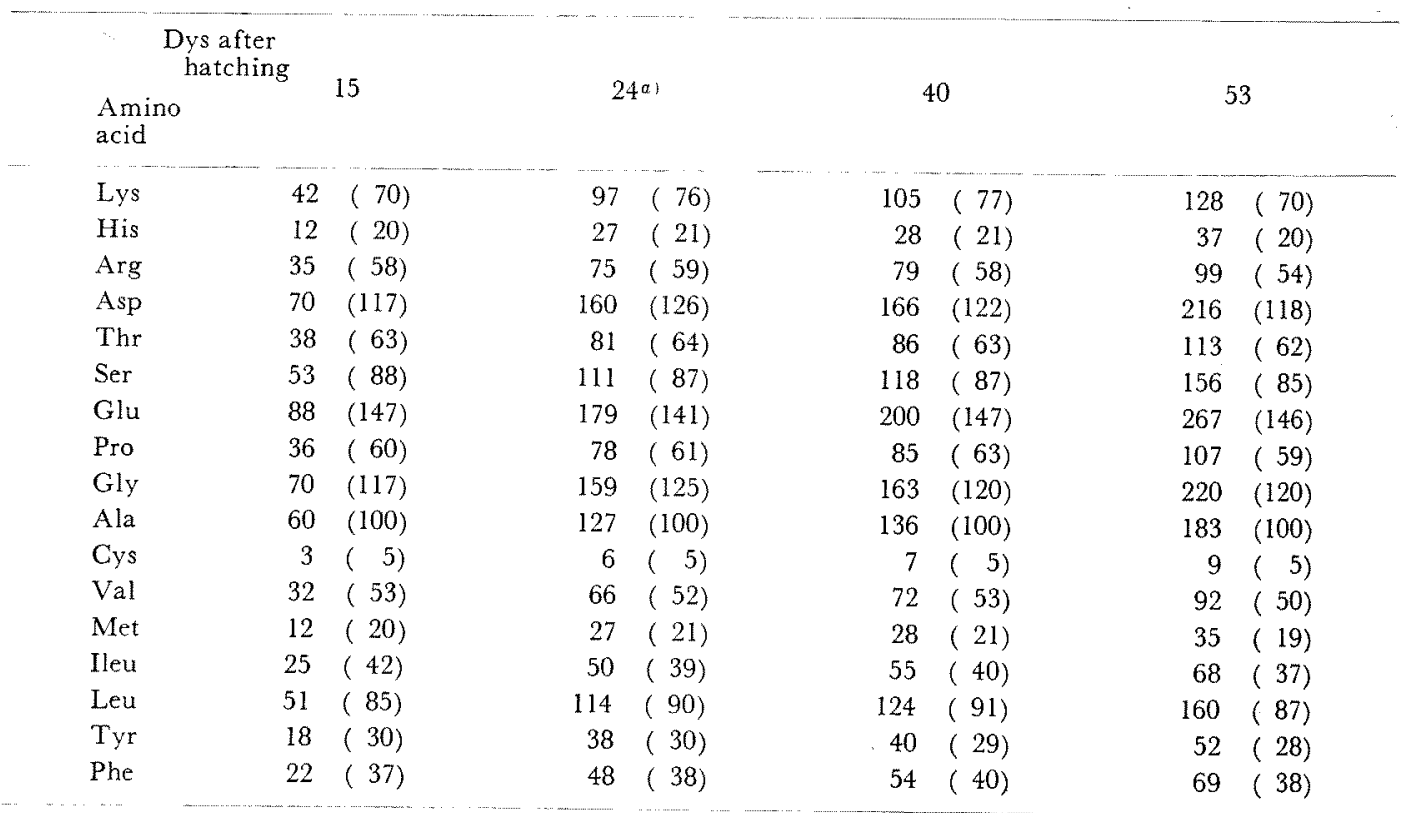

a) A very similar data which was obtained one year before was used to prepare the amino acid mixture feed. 
The constancy of the relative amino acid composition which is independent of the diets taken in the toad just metamorphosed

The amino acid composition of little toads, 65 days after hatching, cultured by the artificial feed and fish meal in their tadpole period, was analyzed by the same method as described above. In spite of the different feeds taken, the relative amino acid composition of the toad was quite similar and the some constancy of the relative amino acid composition was also found between the growing tadpoles and the metamorphosed toad. The results are demonstrated in Table IV

TABle IV. The Amino Acid Composition of TADPoles GRown BY Different Diets ( $\mu$ mole amino acid per 100 individuals)

Tadpoles were grown as in Table II and killed 53 days after hatching. In the parenthesis, the percentage to alanine is given.

\begin{tabular}{lrlrlrl}
\hline & \multicolumn{2}{c}{$\begin{array}{c}\text { Arificial } \\
\text { feed }\end{array}$} & \multicolumn{2}{c}{ Fish meal } & \multicolumn{2}{c}{$\begin{array}{c}\text { Without } \\
\text { feed }\end{array}$} \\
\hline Lys & 264 & $(68)$ & 315 & $(62)$ & 39 & $(87)$ \\
His & 86 & $(22)$ & 97 & $(19)$ & 9 & $(20)$ \\
Arg & 220 & $(56)$ & 279 & $(55)$ & 27 & $(60)$ \\
Asp & 420 & $(108)$ & 579 & $(115)$ & 56 & $(124)$ \\
Thr & 230 & $(59)$ & 297 & $(59)$ & 30 & $(67)$ \\
Ser & 321 & $(82)$ & 396 & $(78)$ & 40 & $(89)$ \\
Glu & 552 & $(146)$ & 707 & $(140)$ & 63 & $(140)$ \\
Pro & 267 & $(68)$ & 331 & $(66)$ & 28 & $(62)$ \\
Gly & 598 & $(153)$ & 736 & $(146)$ & 56 & $(124)$ \\
Ala & 390 & $(100)$ & 505 & $(160)$ & 45 & $(100)$ \\
Cys & 21 & $(5)$ & 21 & $(4)$ & 2 & $(4)$ \\
Val & 186 & $(48)$ & 240 & $(48)$ & 25 & $(56)$ \\
Met & 62 & $(16)$ & 93 & $(18)$ & 9 & $(20)$ \\
Ileu & 147 & $(38)$ & 192 & $(38)$ & 20 & $(44)$ \\
Leu & 322 & $(83)$ & 403 & $(80)$ & 43 & $(96)$ \\
Tyr & 118 & $(30)$ & 148 & $(29)$ & 14 & $(31)$ \\
Phe & 144 & $(37)$ & 185 & $(37)$ & 19 & $(42)$ \\
\hline
\end{tabular}

where the values are expressed in the same manner as in Table III. The amino acid composition of starved tadpoles cultured without feed for 53 days is also shown in Table IV.
The assimilation of amino acids by toads

An apparent conversion rate of each amino acid in the feed by the tadpoles is shown in Table $\mathrm{V}$, dividing the amount of the amino

Tale V. Conversion Rate of Amino acids IN FeEd by TADPOLES

The amount of amino acids in feeds given was divided by the amount of amino acid found in the whole carcasses of tadpoles cultured for 53 days.

\begin{tabular}{lccc}
\hline & $\begin{array}{c}\text { Artificial } \\
\text { feed }\end{array}$ & $\begin{array}{c}\text { Forced } \\
\text { cannibalism }\end{array}$ & Fish meal \\
\hline Lys & 4.64 & 1.33 & 7.60 \\
His & 4.21 & 1.35 & 6.07 \\
Arg & 4.12 & 1.32 & 5.72 \\
Asp & 4.23 & 1.34 & 5.21 \\
Thr & 4.13 & 1.33 & 5.17 \\
Ser & 3.84 & 1.33 & 4.68 \\
Glu & 4.73 & 1.33 & 5.50 \\
Pro & 3.95 & 1.33 & 4.49 \\
Gly & 3.42 & 1.33 & 4.24 \\
Ala & 4.41 & 1.33 & 5.48 \\
Cys & 4.10 & 1.33 & 7.88 \\
Val & 5.16 & 1.33 & 7.64 \\
Met & 5.87 & 1.34 & 9.45 \\
Ileu & 4.67 & 1.34 & 7.42 \\
Leu & 4.42 & 1.33 & 6.02 \\
Tyr & 3.70 & 1.35 & 5.48 \\
Phe & 4.35 & 1.33 & 5.46 \\
\hline
\end{tabular}

acids taken by the amount of the amino acids found in the whole carcasses of hundred individuals after 53 days culture from hatching. Among the three different feed groups tested, the highest efficiency was found in the cannibalism group where each of component amino acid in the prey was accumulated in the same rate in the predator. The lowest amino acid assimilation rate was found in the fish meal group where protein was a main source of the energy for growth. In the artificial feed group, a better amino acid assimilation was obtained than in the fish meal group. In both of the artificial feed and fish meal groups, the assimilation rate of each amino acid diversed widely suggesting that methionine was a limiting factor for the amino acid assimilation. 
The amino acid composition of Bull frog and African claw toad

The relative amino acid composition of Bull frog and African claw toad is shown in Table VI where the samples from each 10

\section{Tale VI. Relative Amino Acid Composition of Bull Frog and African Claw TOAD}

Values are expressed as the percentage to alanine. Each 10 individuals were killed about two weeks after the metamorphosis. No feeds was given during the metamorphosis (between 53rd day from hatching and the sampling day).

\begin{tabular}{|c|c|c|}
\hline & Bull frog & African claw toad \\
\hline Lys & 54 & 95 \\
\hline His & 20 & 37 \\
\hline Arg & 53 & 100 \\
\hline Asp & 91 & 150 \\
\hline Thr & 50 & 76 \\
\hline Ser & 69 & 87 \\
\hline Glu & 118 & 212 \\
\hline Pro & 71 & 73 \\
\hline Gly & 172 & 121 \\
\hline Ala & 100 & 100 \\
\hline $\mathrm{Cys}^{a\}}$ & $(+)$ & $(+)$ \\
\hline Val & 48 & 73 \\
\hline Met & 10 & 14 \\
\hline Ileu & 39 & 67 \\
\hline Leu & 66 & 114 \\
\hline Tyr & 21 & 48 \\
\hline Phe & 34 & 73 \\
\hline
\end{tabular}

a) Only dectable amount of cystine was found on column chromatograms.

individuals are prepared as described above. Bull frogs were fed by the artificial feed for about two months to obtain metamorphosed frogs and African claw toads were cultured by the same way but started from the fertilized eggs and they were killed two weeks after completion of the metamorphosis. The relative amino acid composition of Bull frog was very similar to that of Japanese toad but that of African claw toad was quite different as compared with that of Japanese toad.
Unidentified ninhydrin-positive materials in tadpoles and toads

In Fig. 2, a part of the column chromatogram of the amino acid analysis of the eggs of Japanese toad is shown where two small unidentified peaks are seen just before the aspartic acid peak. These two small peaks are common to young tadpoles of the anurans tested but they were not detectable after the metamorphosis of these tadpoles.

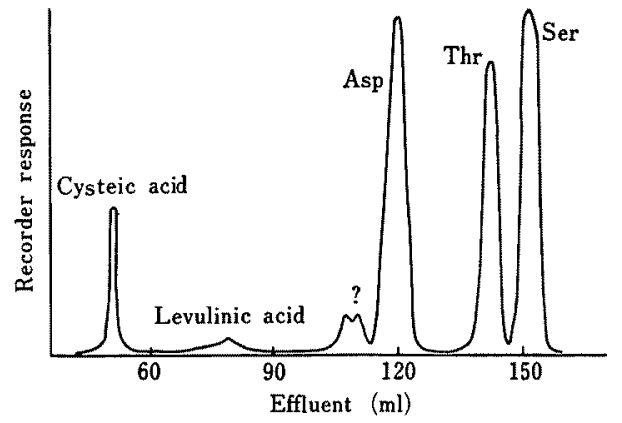

FIG. 2. Unidentified Ninhydrin-positive Peaks in Tadpoles.

A part of column chromatogram of the amino acid in Japanese toad egg. The presence of two small peaks (? in the figure) was common in the tadpoles of Japanese toad, bull frog and African clawed toad. Cysteic and levulinic acid were detected only in the egg.

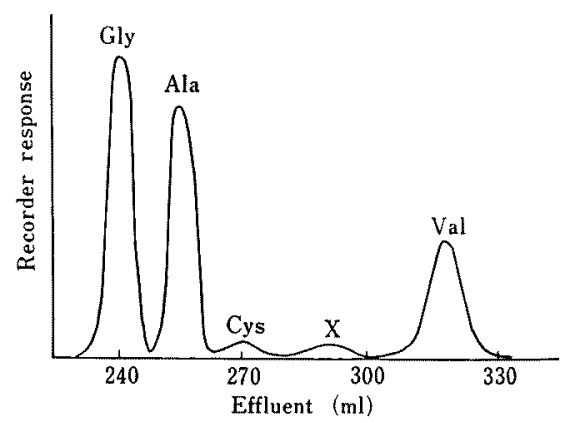

FIG. 3. Unidentified Ninhydrin-Positive Peak Common in Japanese Toad, Bull Frog and African Clawed Toad.

The samples were prepared using little adult forms just after the metamorphosis. 
Peaks corresponded to cysteic acid and levulinic acid were detectable only in the eggs of Japanese toad and they were disappeared after hatching. Another unidentified peak was detected from Japanese toad between the peaks of cystine and valine in the chromatogram of amino acid analysis after the metamorphosis finished. The same peak was common to Bull frog and African claw toad, but this peak was not found in the tadpoles. The chromatogram is shown in Fig. 3.

\section{DISCUSSION}

A satisfactory growth was obtained by culturing tadpoles with an artificial feed. The powered feed was used in this experiments. However, a crumbled feed was also useful as well as the mashed feed by a separate feeding experiments of adpoles which is not described in this paper. It was observed that a nutritional disturbance hindered the achievement of the metamorphosis. When tadpoles were grown by powdered maize only, no metamorphosis took place before the death of tadpoles. Also no normal metamorphosis occured when fish meal alone was given to tadpoles.

The initial growth of the hatched tadpoles started with rapid water intake. When tadpoles were kept without feeds, a little body weight increase was observed after this water intake. At the end of this experimental period, these starved tadpoles showed approximately $10 \%$ of the dry weight gain, but this value may include experimental errors. The culture vessels were not covered to prevent dropping dust which might be only one possible solid matter source. The highest feed efficiency was found in the artificial cannibalism group, though the amount of feed taken was the least in this group, probably due to large water content in the prey. Probable reasons why the feed efficiency was so high in the cannibalism group might be as follows. 1. The amino acid composition of the prey was just the same as that of the predator which enabled the maximum accumulation of amino acid taken for tadpoles (this conversion rate was 1.3 for each of all kinds of amino acid analyzed). 2. Fewer uptake of the diet enhanced the digestibility of the feed. Low amino acid efficiency for fish meal might be attributed to improper amino acid composition of the diet and overfeeding.

Poor effect of the amino acid mixture feed might be attributed to the fact that this feed was easily dispersible in water rather than the other feeds so that the amount of the feed taken by tadpole was decreased.

The relative amino acid composition of the tadpoles was very similar, independent of the feeds given, growth stages and the size of tadpoles, but some difference was found among species after metamorphosis. The similarity was found between Japanese toad and Bull frog, though the former had higher percentage of cystine. The amino acid composition of African claw toad was different from the other two species. Three unidentified ninhydrin-positive peaks were detected on the column chromatograms of amino acid analysis for whole carcass of tadpoles, toads and frog. However, whether these substances were specific to their developmental stages or not is yet unknown.

Acknowledgement. The authors wish to thank Mr. K. Takada of this laboratory for the amino acid analysis. Thanks are also due to Miss F. Ichikawa for her help in tadpole culture. 